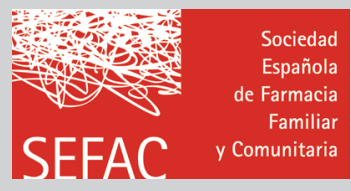

\title{
Una nueva etapa para seguir creciendo
}

\author{
Nicanor Floro Andrés Rodríguez
}

Director de FARMACÉUTICOS COMUNITARIOS

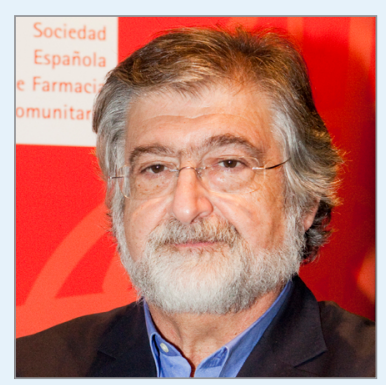

Nicanor Floro Andrés Rodríguez

\section{PALABRAS CLAVE}

Investigación en farmacia, resultados en salud, indexación, factor de impacto, nueva etapa

\section{KEYWORDS}

Research in pharmacology, results in health, indexing, impact factor, new phase
Desde los años 90 del pasado siglo la Farmacia Comunitaria española ha ido asumiendo mayores responsabilidades en la obtención de resultados definidos y medibles en términos de salud para los pacientes que necesitan medicamentos. Para ello ha desarrollado nuevos Servicios Profesionales Farmacéuticos (SPF) que complementan, desarrollan y aportan nuevo valor a la dispensación de los fármacos. El proceso tuvo el carácter de innovación similar al de la incorporación de toda nueva tecnología sanitaria y desde el primer momento se apoyó en la realización de estudios de investigación de metodología científica con el fin de evaluar los resultados en la mejora de la salud de pacientes y usuarios y demostrar de manera rigurosa que la causa de esa mejora era, precisamente, la prestación de esos nuevos SPF que el farmacéutico comunitario incorporó a su actividad tradicional.

La difusión de estos trabajos de investigación se hizo imprescindible para conseguir la extensión y consolidación de su práctica y dar a conocer a la Sociedad que las farmacias comunitarias constituyen uno de los recursos asistenciales más eficientes de la Atención Primaria. Las comunicaciones a congresos en formato póster fue el primer método por el que los farmacéuticos comunitarios que investigábamos dábamos a conocer a los compañeros los resultados de las nuevas actividades y servicios. La evolución del número de comunicaciones en los congresos de SEFAC desde el primero, celebrado en 2004 (46 pósteres), hasta el reciente VIII congreso de Alicante 2018 (más de 400) es un indicador de la vitalidad de nuestra Sociedad y del creciente interés de los farmacéuticos comunitarios por la investigación científica en relación a las actividades profesionales. Muy pocos de estos trabajos llegaban a publicarse como artículos de investigación en revistas del sector biomédico, de difícil acceso para el farmacéutico comunitario, y por lo tanto no alcanzaban la difusión necesaria para que tanto resultados como metodología llegasen a ser conocidos por la comunidad científica, sirviendo de base para nuevos estudios que irian sustentando el avance profesional.

En el año 2009 la Farmacia Comunitaria española sentía la necesidad de disponer de una revista científica propia en la que dar a conocer la mucha y buena investigación que en este ámbito se estaba realizando. La consolidación de SEFAC como sociedad científica de referencia estaba dando lugar a nuevos e interesantes proyectos de investigación, muchos de ellos en colaboración con las sociedades científicas médicas, cuyos resultados debían difundirse. Desde 2006 a 2008 se publicó e-farmacéutico comunitario, que dirigía Paco Martínez y publicó ya algunos artículos de investigación. En junio de 2009 comenzó la actual etapa de Farmacéuticos Comunitarios, cabecera utilizada anteriormente por SEFAC de la Comunidad Valenciana en dos números dirigidos por Miguel Cano.

En el editorial del número anterior (http://farmaceuticoscomunitarios.org/es/ journal-article/mirar-atras-seguir-adelante) y en la ponencia que impartí hace unas semanas en Alicante repasé los resultados de los nueve años transcurridos desde entonces. Los datos reflejan la consolidación de una revista científica que difunde buena parte de la investigación que se está realizando en España en el ámbito de la Farmacia Comunitaria, tanto a nivel individual, como de grupos de trabajo y los resultados de estudios llevados a cabo por SEFAC y en colaboración con otras sociedades científicas e instituciones, con las que participa en proyectos de investigación y en documentos de consenso. Numerosas bases de datos científicas de alcance internacional y repertorios de evaluación de publicaciones periódicas reconocen esta evolución con la inclusión de nuestra revista como una fuente primaria de calidad (http:// www.farmaceuticoscomunitarios.org/es/ indexacion). La web recibió, en el primer trimestre de 2018, 34.566 visitas de 19.734 usuarios, con un 92\% de usuarios 
que repetían visita y un 57\% de accesos desde fuera de España. Estos indicadores muestran que estamos alcanzando una difusión importante que, sin duda, se irá reflejando en una influencia creciente de nuestra revista en el panorama de la investigación en Farmacia Comunitaria.

No se trata de una labor individual, sino del trabajo conjunto de un gran equipo, en el que se van sucediendo las personas pero permanece una filosofía de trabajo: estimular y ayudar a difundir la investigación que se lleva a cabo en nuestras farmacias.

Se inicia ahora una nueva etapa en la que ya no ejerceré como director de la revista. Tras estos nueve años dirigiendo Farmacéuticos Comunitarios quiero manifestar mi agradecimiento al trabajo de todo el equipo: comité editorial, revisores, coordinadores, secretaría, edición y maquetación, y especialmente a autores y lectores. Todos son imprescindibles para que nuestra revista siga progresando. Agradezco también al apoyo y la confianza que los presidentes Marichu Rodríguez y Jesús C. Gómez dieron a mi labor en todo este tiempo.

La investigación sobre la práctica asistencial en nuestras farmacias debe continuar y la publicación de sus resultados también. No es sencillo, requiere formación, disposición, motivación y el esfuerzo de dedicar a ello buena parte del tiempo libre que el trabajo diario nos deja. Los más de 400 pósteres presentados en Alicante deben convertirse en artículos científicos. Para ello, entre otras herramientas, SEFAC pone a disposición de los autores una
Comisión de Investigación cuyos miembros revisan los proyectos que los socios, los grupos de trabajo y las instituciones colaboradoras quieren poner en marcha. También proponen los cambios que creen necesarios para mejorar su metodología, procedimientos, validez, redacción, etc. El comité editorial y el científico de la revista hacen una labor similar con los manuscritos ya elaborados.

Conseguir un factor de impacto importante y la indexación en las más prestigiosas bases de datos siguen siendo los objetivos fundamentales que perseguimos. Para lograrlo necesitamos la implicación de todos los socios y de los colaboradores cuyos trabajos se relacionan con la Farmacia Comunitaria, y ser conscientes de que la investigación es un elemento diferenciador de gran valor para los profesionales científicos en general y sanitarios en particular e imprescindible para el progreso y el desarrollo de las sociedades avanzadas. Todo esto debe servir para seguir creciendo en las solicitudes de publicación de un mayor número de artículos originales, especialmente estudios experimentales, donde se investiguen resultados en salud, revisiones sistemáticas y metaanálisis, casos clínicos, etc.

En el próximo número toma el relevo en la dirección de la revista Luis Salar Ibáñez, cuyo prestigio profesional y amplia actividad docente e investigadora no necesito presentar. Miembro ya de los comités científico y editorial, estoy seguro de que le dará un renovado impulso y conseguirá más pronto que tarde alcanzar estos objetivos. Contará con mi colaboración y apoyo incondicional. 